\title{
Oxide Cathode Base Metal Studies
}

\author{
Ralph Forman and Glenn F. Rouse
}

\begin{abstract}
A method for comparing the properties of two oxide cathodes, one with a highpurity-nickel base and the other with a nickel base containing a small percentage of magnesium, is discussed. Data are presented showing the effect of magnesium on the rate of electrolytic activation and life of an oxide cathode. The influence of the cathode and anode on pulsed current decay at high current densities is also discussed.
\end{abstract}

\section{Introduction}

During the construction of an oxide cathode and the tube of which it becomes a part, there exists a multiplicity of factors that may enter to affect the subsequent performance of the cathode. Solutions to the problem of obtaining unambiguous data on any of these factors would lead to a much better understanding of the physical nature of the emissive properties of an oxide cathode.

The composition of the metal that serves as a base for the oxide coating is widely recognized as a source of uncertainty in cathode behaviour. In a majority of cases the base is made of nickel that contains minute amounts of certain other metals. Studies of the role played by these other metals in connection with the emission properties of the cathode have been made by several investigators $[1,2,3,4]^{1}$ and are still a source of considerable current interest. The inadequacy of the information regarding the role played by the base metal is brought out by the fact that a tube manufacturer still feels compelled to accept or reject a new melt of cathode nickel, not on the basis of available information about the composition of the material, but on the basis of test results obtained with one or more production tube types.

The work described in this paper is part of an investigation undertaken to obtain additional information about the nickel-base metal. More specifically, this paper deals with the study of the influence of magnesium in cathode nickel on the thermionic performance of an oxide cathode. The choice of magnesium was prompted by its relatively high reducing action on an oxide coating [5].

A description is given of two distinct phases of the work. One is the development of suitable test apparatus and proper testing technique. The other is the analysis of the results obtained from a comparison of a cathode on high-purity nickel with one on a base of magnesium nickel.

\section{Description of Apparatus and Methods}

\section{Test Diode}

A logical method for evaluating the effects that result when a small amount of magnesium is added to nickel is to compare the performance of two cathodes, one on high-purity nickel, the other on nickel containing magnesium, both of which have been exposed

\footnotetext{
1 Figures in brackets indicate the literature references at the end of this paper.
}

equally to all other factors that could influence their behavior. The best practical means of doing this would seem to be the use of a properly designed double diode. Particular features of the doublediode structure that was used are illustrated in figure 1.

A channel made from high-purity nickel is bent and welded to form a square frame to which the cathode can be fastened (see fig. 1, a). A flat, pure tungsten heater, uncoated, is positioned parallel to the plane of the frame and equidistant from the two faces. Squares of the sheet metals that serve as the bases of the two cathodes to be compared (one is illustrated in fig. 1, b) are fastened to the cathode frame so as to enclose the heater filament com-
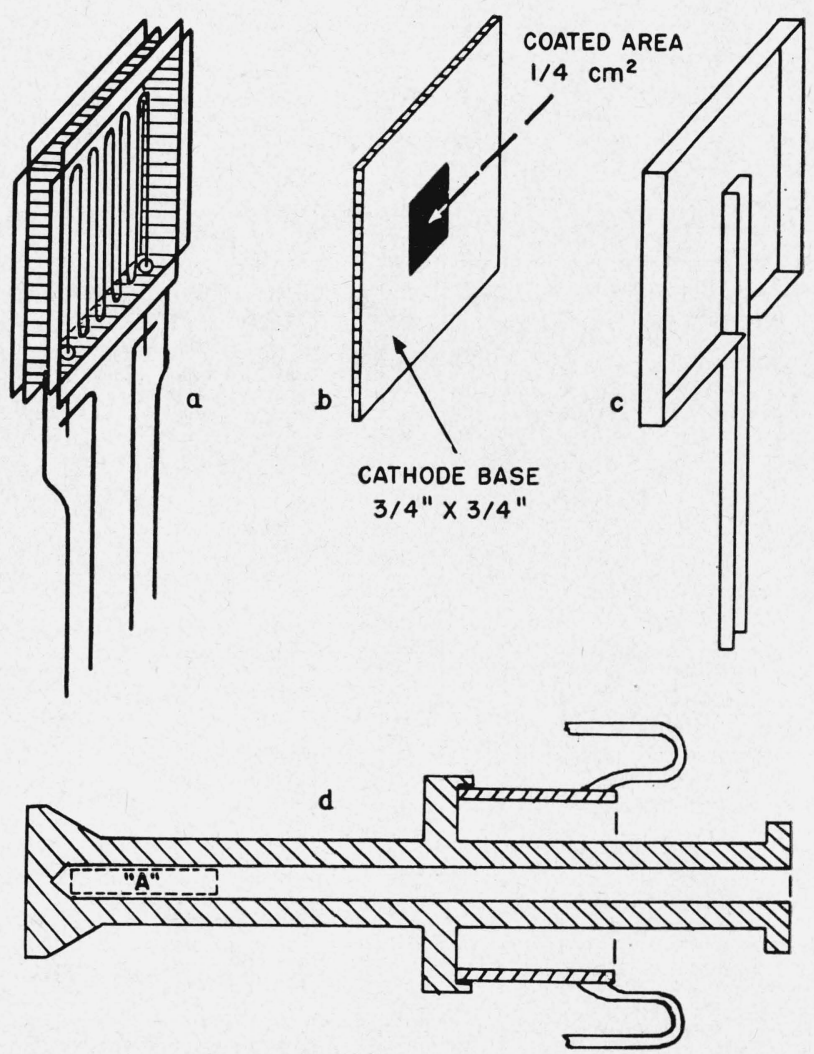

Figure 1. Component parts of double diode.

a, Cathode mount; b, cathode; c, sheet anode; d, water-cooled anode. 
pletely. This is done, of course, after application of the emission coating. The diode structure is completed by the addition of two anodes. In one case the anodes consist of flat sheets with edges turned to increase rigidity (see fig. 1, c). This type of anode is quite easy to make, but it has the disadvantage of low thermal dissipation. Another type of anode is illustrated in figure $1, d$. This consists of a body, machined from a "Grade A" nickel rod, to which a kovar cylinder is brazed so as to make possible a glass-metal seal. An advantage inherent in this design is that the part of the anode nearest the cathode can be very effectively heated or cooled as desired. To accomplish the heating, a coiled tungsten filament, mounted on a press that permits rough evacuation of the space within the anode, is placed at the position marked A. By controlling the current through the filament, the temperature of the anode head can be held at any desired value as high as $1,000^{\circ} \mathrm{C}$ for as long a time as seems necessary. This makes it possible to degas the anode very thoroughly and to remove any contaminants that can be removed by heating. The cooling is accomplished by replacing the filament with a tube through which water is made to flow against the inner surface nearest the anode face. This method of water cooling was used when tests necessitating high anode dissipation were run on the tube.

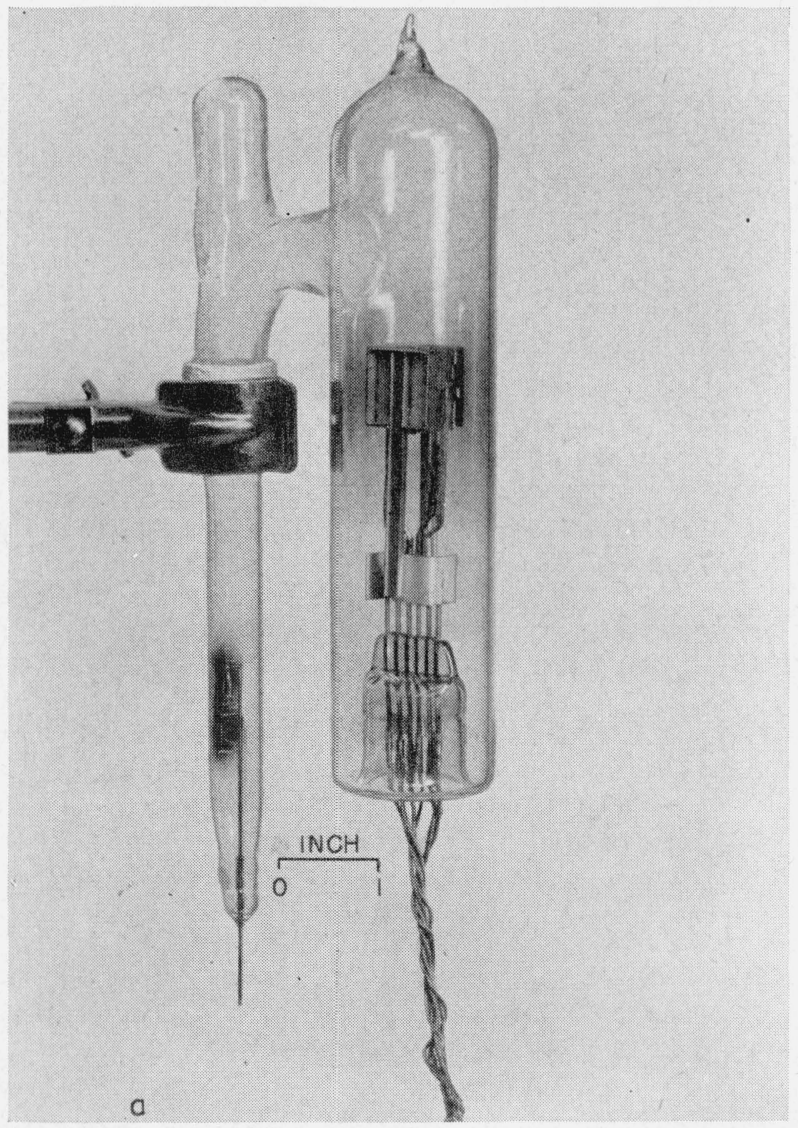

Figure 2 shows the completed diodes, illustrating the two types of anodes. It should be noted that the getters are mounted in side tubes.

Some of the advantages to be gained from the use of a double diode deserve mention. The temperatures of the two cathodes being compared are equal, or very nearly equal, at every instant during life. It is realized, of course, that unequal thermal emissivities will result in temperature differences. However, as the heat radiated by the coated areas is a small fraction of the total heat radiated by the cathode, it seems reasonable to suppose that, if the uncoated areas of the cathode have equal emissivities, variations in the emissivities of the coatings themselves will effect the coating temperatures only slightly. During the processing and the subsequent life of the tube, the two cathodes are, in general, exposed equally to conditions that might affect their initial quality and life performance. A possible difficulty that may arise in the use of a double diode is that material present in one cathode may somehow migrate to the other. This point must be given proper consideration when an interpretation of a given set of data is being made.

In the interest of completeness, another fact, not dependent on tube design, can be mentioned here. It is that the two cathodes are subjected to identical processes, such as cleaning, degassing, hydrogen

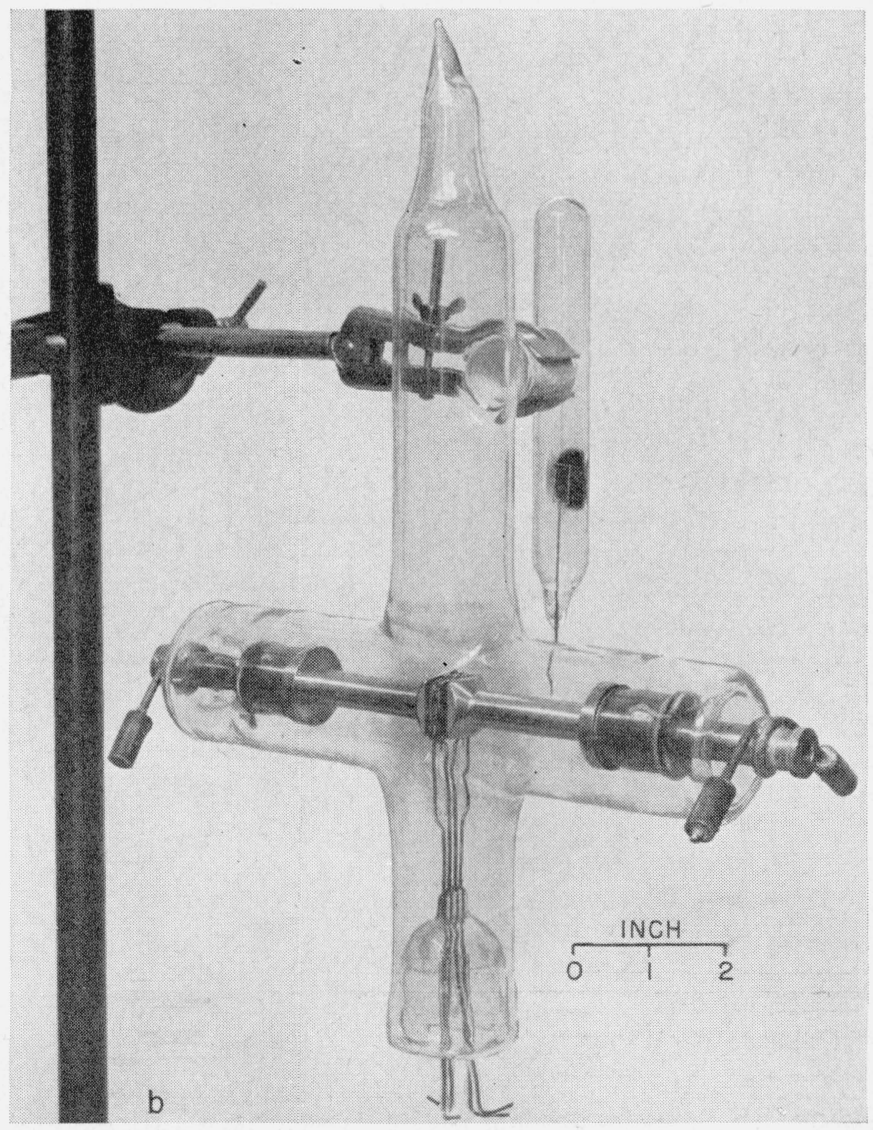

Figure 2. Double diodes.

a, With sheet anodes; b, with water-cooled anodes. 
firing, coating application, etc., previous to insertion into the finished tube.

The following comments cover the more important details in the treatment of tube components and in the processing of a tube.

All nickel parts were chemically cleaned and fired at about $700^{\circ} \mathrm{C}$ in hydrogen that had been passed through an electrodryer. Particular care was taken to make sure that both cathodes, and both anodes as well, were treated exactly alike. The two cathodes were sprayed simultaneously and in such a way that the resulting coatings were essentially identical in all respects. The coating weight was approximately 5 $\mathrm{mg} / \mathrm{cm}^{2}$, the coated area $1 / 4 \mathrm{~cm}^{2}$. The emission coating used contained $57.2 \pm 2$ percent of barium carbonate, $38.8 \pm 2$ percent of strontium carbonate and $4 \pm 0.5$ percent of calcium carbonate. These values conform to a specification of the American Society for Testing Materials.

The completed tube was evacuated on a system of the conventional type containing a three-stage oildiffusion pump with octoil S. A cold trap was located between the diffusion pump and the tube.

The tubes were processed according to a schedule that included an oven bake, degassing of the anodes, breakdown of the coating by temperature treatment, another degassing of the anodes, and an ageing period. Details pertinent to any particular experiment will be given in the description of the experiment.

Temperatures were measured with an optical pyrometer. All values quoted are brightness temperatures.

Data are reported in the literature that clearly indicate that the magnitude of the direct-current emission obtainable from an oxide cathode differs markedly from that of the peak emission observed when microsecond current pulses are used. For instance, Dillinger [6] has shown that a directcurrent current density of $19 \mathrm{amp} / \mathrm{cm}^{2}$, can be drawn from a well-activated cathode on a pure nickel base $\left(1,150^{\circ} \mathrm{K}\right)$, whereas Coomes [7] has reported peak emission densities as high as $90 \mathrm{amp} /$ $\mathrm{cm}^{2}$, from a cathode on a pure-nickel base $\left(1,075^{\circ} \mathrm{K}\right)$. In the latter case 1 - $\mu$ sec current pulses were used.

It was believed, however, that a better correlation between direct-current and pulsed emission data might be found if pulses of relatively long duration were used. If this were found to be true, one would then be in a position to learn much about direct-

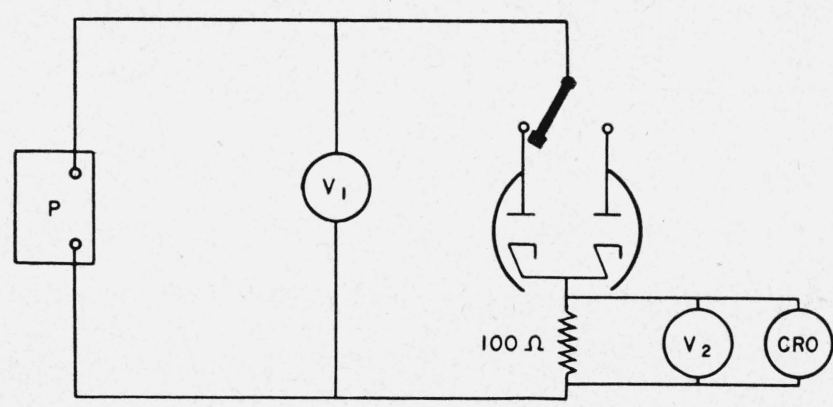

Figure 3. Pulse-measurement circuit, block diagram. current emission while taking advantage of the pulse technique, the advantage being the ability to measure temperature-limited emission without excessive heating of tube parts. With this idea in mind, pulsed measurements were made on the experimental diodes. Square wave voltage pulses of $250 \mu$ sec duration were used. Setting the repetition rate at $40 \mathrm{pps}$ gave a duty cycle of 1 percent. A block diagram of the circuit used for the pulse measurements is shown in figure 3. $P$ is the pulsing circuit. The peak reading voltmeters, $V_{1}$ and $V_{2}$, are type GR-1800A. Meter $V_{1}$ is provided with a capacity-compensated voltage divider that increases its range by 10 . Meter $V_{2}$ is calibrated to read the voltage developed by the cathode current across the $100-\Omega$ noninductive resistor. The CRO in parallel with meter $V_{2}$ is a DuMont 248 oscillograph. Connections are made directly to the vertical plates of the latter instrument, whose sensitivity is known in terms of volts/ inch.

\section{Discussion of Experimental Results}

\section{Cathode Performance Studies}

The magnesium-nickel alloy referred to in this paper is INCO T-17652, for which the manufacturer specifies the additives as 0.18 percent of $\mathrm{Mg}$ and 0.01 percent for both $\mathrm{C}$ and $\mathrm{Si}$.

The high-purity nickel used in this experiment is INCO 1001 electrolytic nickel. Spectrographic analysis of this nickel shows approximately 0.01 percent of $\mathrm{Cu}$ and $\mathrm{Pb}$. Traces of $\mathrm{Mg}, \mathrm{Mn}$, and $\mathrm{Si}$, appear in quantities less than 0.01 percent.

For ease of description, the magnesium-nickel alloy and the high-purity electroly tic nickel will be referred to as $\mathrm{Mg}$-Ni and 1001, respectively. Likewise, cathodes made on these materials will be referred to as $\mathrm{Mg}-\mathrm{Ni}$ and 1001 cathodes.

The first tube for which experimental results are presented was one in which one of the cathodes was on 1001 nickel and the other on $\mathrm{Mg}-\mathrm{Ni}$. The parts of the tube not of 1001 nickel were the tungsten heater, short lengths of tungsten extending inside the glass press, the emission coatings, and an RCA batalum getter in a side arm (see fig. 2,a). Immediately following breakdown of the coating, during which the maximum temperature reached was $950^{\circ} \mathrm{C}$, the cathode temperature was set at $800^{\circ} \mathrm{C}$, and a direct-current potential of $100 \mathrm{v}$. was applied to each anode. Data showing the variation of current with time were taken. Curves of these data are shown in figure 4, A being for the 1001 cathode, B for the $\mathrm{Mg}-\mathrm{Ni}$ cathode. The rate of increase of current exhibited by the $\mathrm{Mg}-\mathrm{Ni}$ cathode is markedly lower than that for the 1001 cathode.

Before any significance can be attributed to this difference in behavior, it is necessary to know whether the curve for the reference cathode, that is, the 1001 cathode, truly represents its behavior. That is to say, would the activation curve for the 1001 cathode have been quite similar to the one shown if the $\mathrm{Mg}$ Ni eathode had not been present? Also, what statis- 


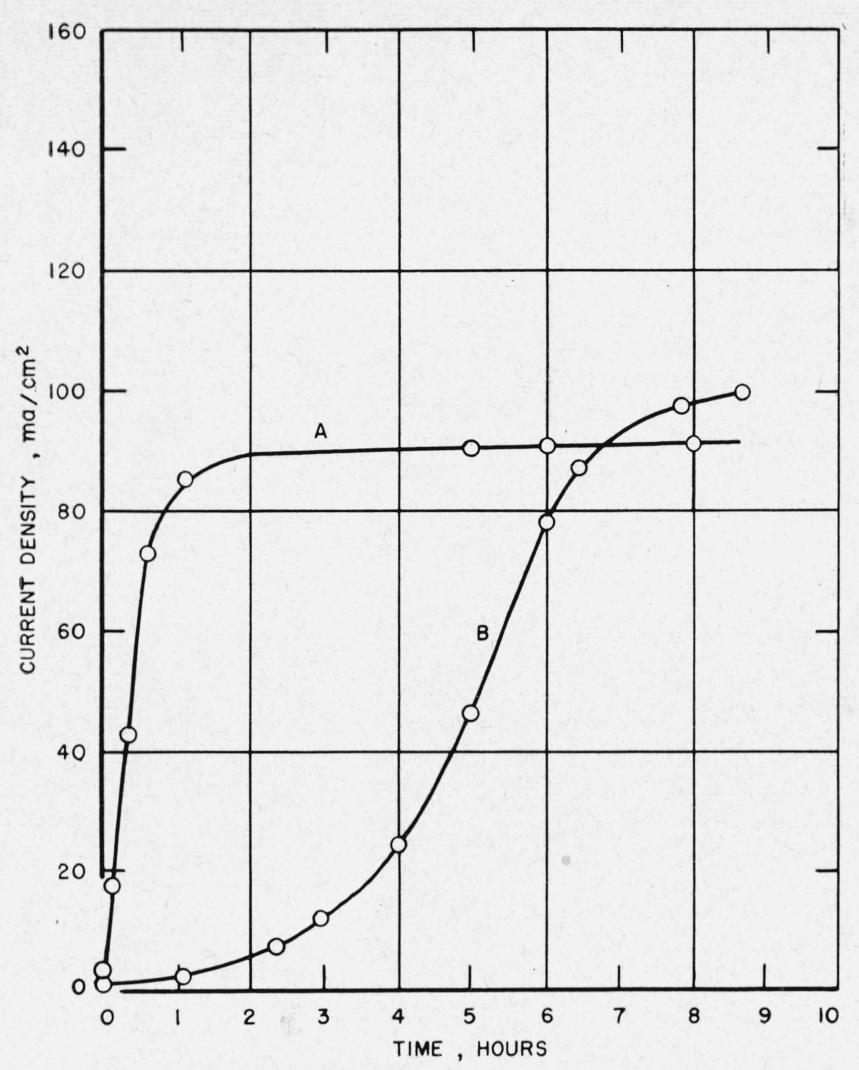

Figure 4. Activation curves.

Cathodes with: A, 1001 nickel base; B, Mg-Ni base.

tical variation in time dependence should one expect in the curve for the 1001 cathode?

Information bearing on these questions was obtained from a tube that differed structurally from the one described in just one respect, namely, the $\mathrm{Mg}-\mathrm{Ni}$ cathode was replaced by a 1001 cathode. Thus both cathodes were of the 1001 type. Care was taken to make the treatments and conditions, to which these cathodes were subjected, identical. After the tube had been processed according to a schedule as nearly as possible identical to that for the previous tube, similar sets of data were taken. Curves of these data are shown in figure 5 .

It will be observed that curve $\mathrm{A}$ of figure 4 is very similar to the curves of figure 5. One may infer from this that magnesium did not migrate from the one cathode to the other, or, if it did, that it had no effect. The separation of the curves of figure 5 may be taken as a measure of the experimental uncertainty to be expected. It seems, therefore, that the curve for the 1001 cathode in figure 4 is a typical one, and it may be concluded that the behaviour of the $\mathrm{Mg}-\mathrm{Ni}$ cathode does differ significantly from that of the 1001 cathode.

The low initial current values in each of these tests are an indication that there was no appreciable thermal activation of the cathodes.

The lower rate of increase of current exhibited by the $\mathrm{Mg}-\mathrm{Ni}$ cathode may be due to the presence of a high resistance layer of some magnesium compound at the metal coating interface. D. A. Wright [8] has reported finding a $\mathrm{MgO}$ interface layer on a $\mathrm{Mg}-\mathrm{Ni}$ cathode.

It should be pointed out here that the absence of thermal activation and the slow rate of electrolytic activation have been observed only when the maximum temperature used in the conversion of the coating was not greater than $950^{\circ} \mathrm{C}$. Evidence obtained from some tubes indicates that high initial currents are obtained from a $\mathrm{Mg}-\mathrm{Ni}$ cathode for which the temperature during breakdown reaches a maximum of $1,050^{\circ} \mathrm{C}$, and any growth of current occurring after breakdown is very rapid.

Immediately following these tests that were made to obtain the data plotted in figures 4 and 5 , the tubes involved were aged for several hours, and then pulse tests were made. It was found that both the 1001 cathodes and the Mg-Ni cathode could supply peak current densities of about $4 \mathrm{amp} / \mathrm{cm}^{2}$. This result has been found to be rather generally true for cathodes in other similar tubes.

The tubes described above were of the type that is unsuited for direct-current life testing at normal cathode temperature because of the low thermal dissipation of the anodes. A direct-current life test has been conducted on a tube having water-cooled anodes (see fig. 2, b). One cathode has a base of 1001 nickel, the other a base of $\mathrm{Mg}-\mathrm{Ni}$. The anodes were made of grade A nickel. After the tube had

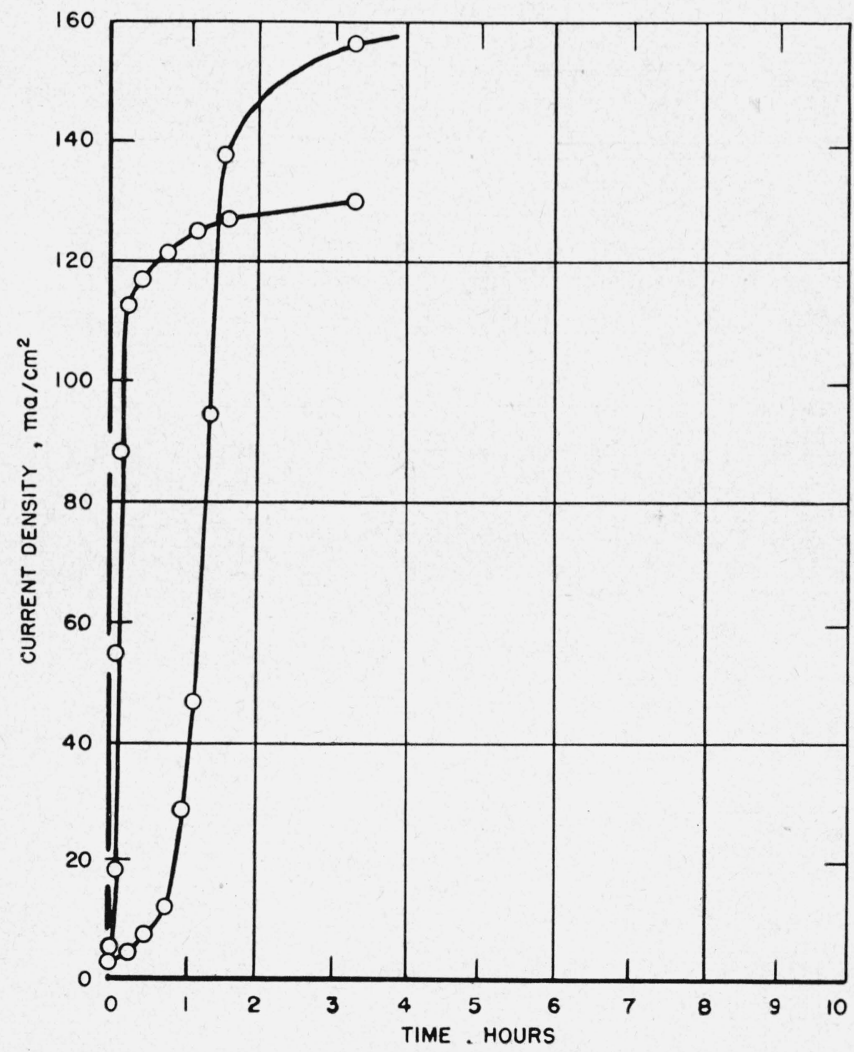

Figure 5. Activation curves.

Each cathode has a 1001 nickel base. 

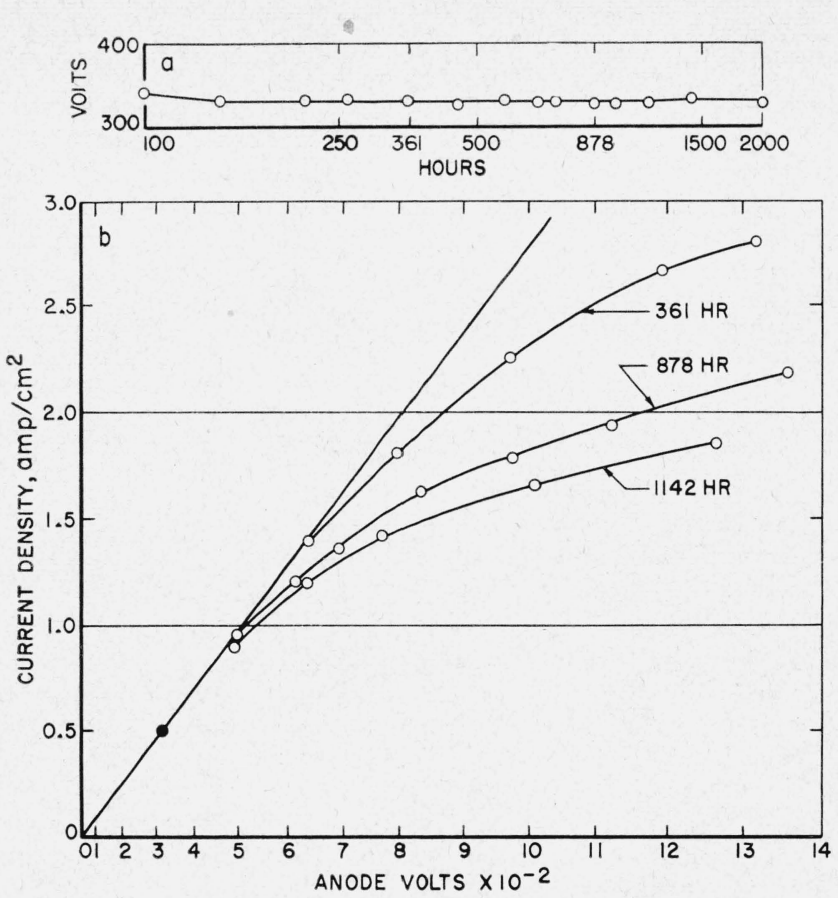

Figure 6. Life-test data for the 1001 cathode.

a, Direct-current data; b, pulse data.
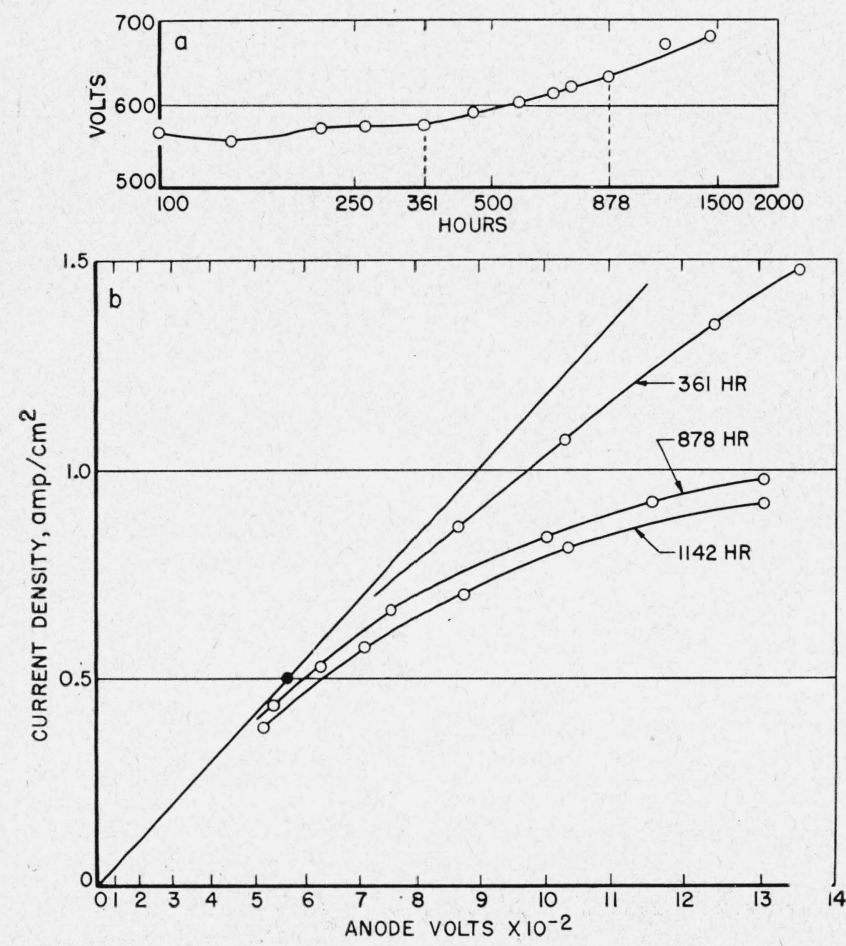

Figure 7. Life-test data for the $M g$-Ni cathode. a, Direct-current data; $b$, pulse data. been processed and certain preliminary measurements were made, it was put on a life test schedule like that used by Kern and Lynch [9] of Bell Telephone Laboratories. The test was started by setting the cathode temperature at $800^{\circ} \mathrm{C}$ and adjusting the anode potentials until the current from each cathode was $125 \mathrm{ma}$ (current density $500 \mathrm{ma} / \mathrm{cm}^{2}$ ). As time passed, the anode potentials were adjusted so as to keep the currents at $125 \mathrm{ma}$. Curves showing the values of potential plotted as a function of time appear in figures 6 , a, and 7 , a, the former being for the 1001 cathode, the latter for the $\mathrm{Mg}-\mathrm{Ni}$ cathode. At intervals the direct-current tests were stopped temporarily, and pulse tests were made. The data for each of three different times, 361, 878, and 1,142 hours, respectively, appear in figures $6, \mathrm{~b}$, and $7, \mathrm{~b}$. The voltage scale is a three-halves power plot, as this gives a linear relation between current and voltage when space-charge current is being drawn. Points that fall on the space-charge line are not plotted in figures $6, b$, and $7, b$, as they are duplicated for each curve.

A study of figure $6, \mathrm{~b}$, reveals that the position of a temperature-limited curve drops progressively as the hours of life increase, a fact that applies also to the point of departure from the space-charge line. However, the break from the space-charge line occurs at a point well above the direct-current operating point (indicated by a filled circle) even after 1,142 hours of life. This behaviour correlates well with that to be deduced from the curve in figure 6 , a, which shows that the voltage required to maintain a space-charge current density of $500 \mathrm{ma} / \mathrm{cm}^{2}$, had not changed during the 1,142 hours of operation. In fact, this cathode was able to maintain a spacecharge current density of $500 \mathrm{ma} / \mathrm{cm}^{2}$, for the duration of the life test period of 3,750 hours.

A study of figure $7, \mathrm{~b}$, also reveals a progressive drop in the position of the temperature-limited curve. In this case, however, the break from the spacecharge line reaches and drops below the directcurrent operating point. Although it is impossible to locate the break exactly, it seems that it is near the direct-current operating point after about 361 hours. One will note that in figure $7, \mathrm{a}$, the upward trend in the voltage value starts at about 361 hours. It can be seen also that the 878-hours curve in figure 7 , b, crosses the $500 \mathrm{ma} / \mathrm{cm}^{2}$ line at a point corresponding to a voltage of 600 or slightly higher. This is a fairly good check of the value corresponding to 878 hours in figure 7 , a.

A direct-current density of $500 \mathrm{ma} / \mathrm{cm}^{2}$, is believed to be a fairly severe life test condition. As the conditions that define end of life for a cathode are arbitrary, it may not be correct to say that the $\mathrm{Mg}-\mathrm{Ni}$ cathode has reached end of life at 1,500 hours. However, it seems quite obvious that the 1001 cathode should have the longer life.

A difficulty that arose while the cathode structure was being sealed in resulted in a noticeable difference between the anode-cathode spacings of the two diodes. As a result, the anode voltage for the $\mathrm{Mg}-\mathrm{Ni}$ cathode is considerably higher than that for the 1001 cathode. 
The effect, if any, which the higher voltage may have had is not known.

Tests somewhat similar to the ones presented here were made by Eisenstein [10] on cathodes having silicon nickel and pure nickel bases. He showed that the emission values obtained for the silicon nickel cathode, using pulses of the order of 1 to 10 microsec, declined more rapidly with time than did the values for the pure-nickel cathode. He attributed this behaviour to an interface layer. It seems likely that the behaviour of the $\mathrm{Mg}-\mathrm{Ni}$ cathode can likewise be attributed to an interface layer.

\section{Decay Phenomena}

In the process of pulse testing the tubes to investigate cathode performance, considerable evidence of pulse-current decay appeared. This effect has been discussed by many authors, Sproull [11], S. Wagener [12], G. R. Feaster [13], D. A. Wright [14], and Metson [15]. Particular efforts were made to discover whether cathodes 1001 and $\mathrm{Mg}-\mathrm{Ni}$ behave in a noticeably different manner with respect to the decay effect. The conclusion was that there is no consistent difference. In general, the appearance of a decay effect in one cathode was accompanied by a similar effect in the other cathode. Although there were sometimes differences in degree, they were not consistent enough to justify the formulation of any definite conclusions.

Some discussions of the decay effect have been based on the tacit assumption that the controlling factors exist in the cathode only. [11, 12]. More recently, views have been expressed to the effect that anode contamination may also play a major role $[13,14,15]$. Conclusive evidence as to exact location of the cause in any given situation is difficult to obtain, because in a simple diode one can presume that any treatment given the anode may affect the cathode and vice versa. Results will be presented now that would seem to indicate that both the cathode and anode can be involved.

A tube like that shown in figure 2, a, was processed, and while still on the pumps was aged at $130 \mathrm{ma} / \mathrm{cm}^{2}$ for 12 hours. Pulse measurements were then made. The results obtained for the 1001 cathode and the $\mathrm{Mg}-\mathrm{Ni}$ cathode were quite similar. Those for the 1001 cathode are plotted in figure 8, a. It may be well to point out just how the decay effect was observed and measured. At each setting of the pulse voltage, readings were taken on the peakreading meters, and the shape of the current pulse was noted on the oscilloscope. When a decay effect showed on the oscilloscope, values of the current at the leading and trailing edges of the pulse were read on the oscilloscope. These readings are recorded on the curves as open and filled circles, respectively. Figure 8, a, reveals that for potentials at and above $700 \mathrm{v}$ there is pulse-current decay accompanied by a departure from the space-charge line.

Immediately following the test just referred to, the anode was held at a temperature of $800^{\circ} \mathrm{C}$ for $5 \mathrm{~min}$, the cathode being kept at normal operating

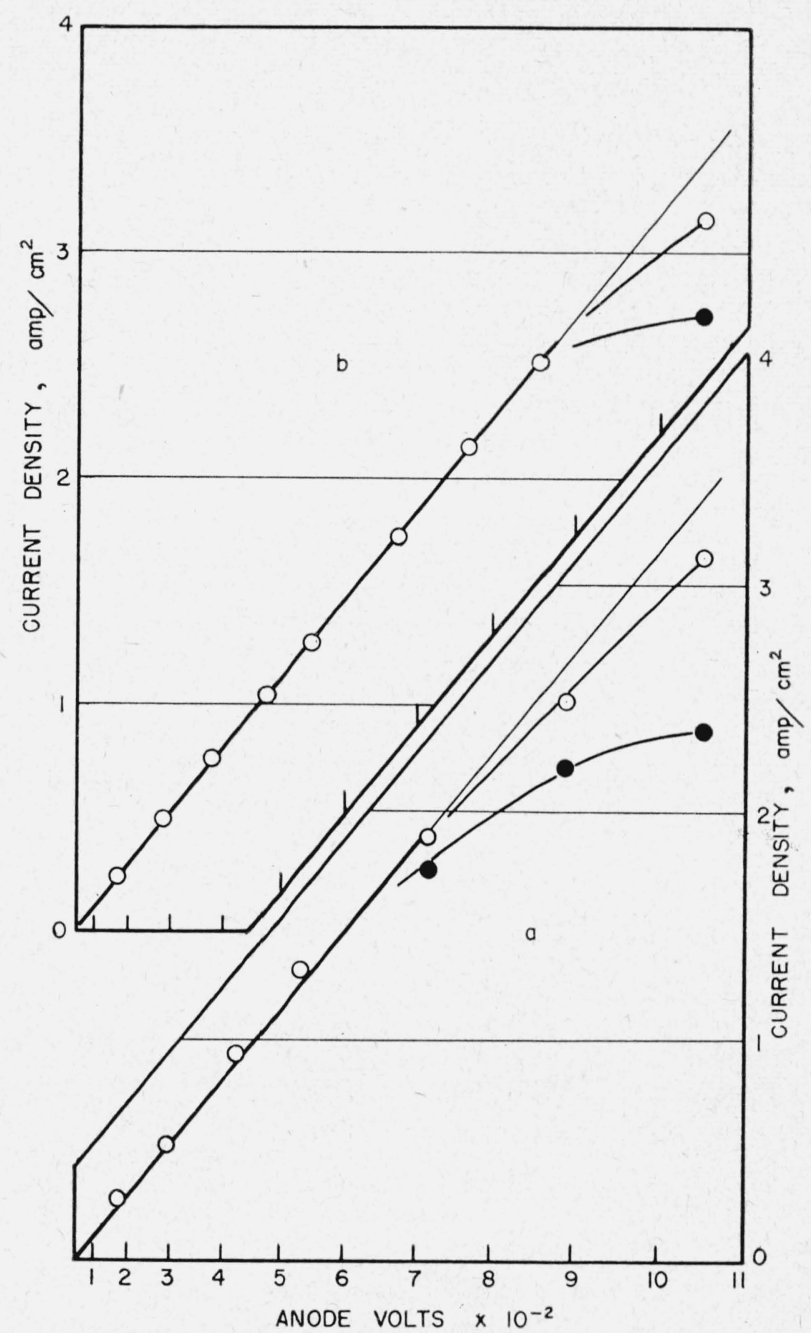

Figure 8. Effect of anode treatment on pulse-current decay. $a$, Before anode is heated; $b$, after anode is heated.

temperature. Any evolved gas was removed by the pump. Repetition of the pulse test yielded data that are shown in figure $8, \mathrm{~b}$. It will be observed that the decay effect and departure from the spacecharge line now begins at about $900 \mathrm{v}$. The change brought about by heating the anode is interpreted to mean that conditions at the anode do influence decay phenomena.

The pulse data in figure 9 were obtained from the $\mathrm{Mg}-\mathrm{Ni}$ cathode of another tube identical to the one discussed above. The open and filled circles have the same significance as in the previous figure. Following this test the cathode was pulse aged at 300-v peak for 67 hours, care being taken to keep the average power into the anode low enough to avoid appreciable heating. Another pulse test then gave the data that are plotted as half-filled circles in figure 9 . The evidence of decay has completely disappeared, and the current values satisfy the space charge equation. Obviously the 67-hour period was sufficient, but perhaps not necessary. These results 


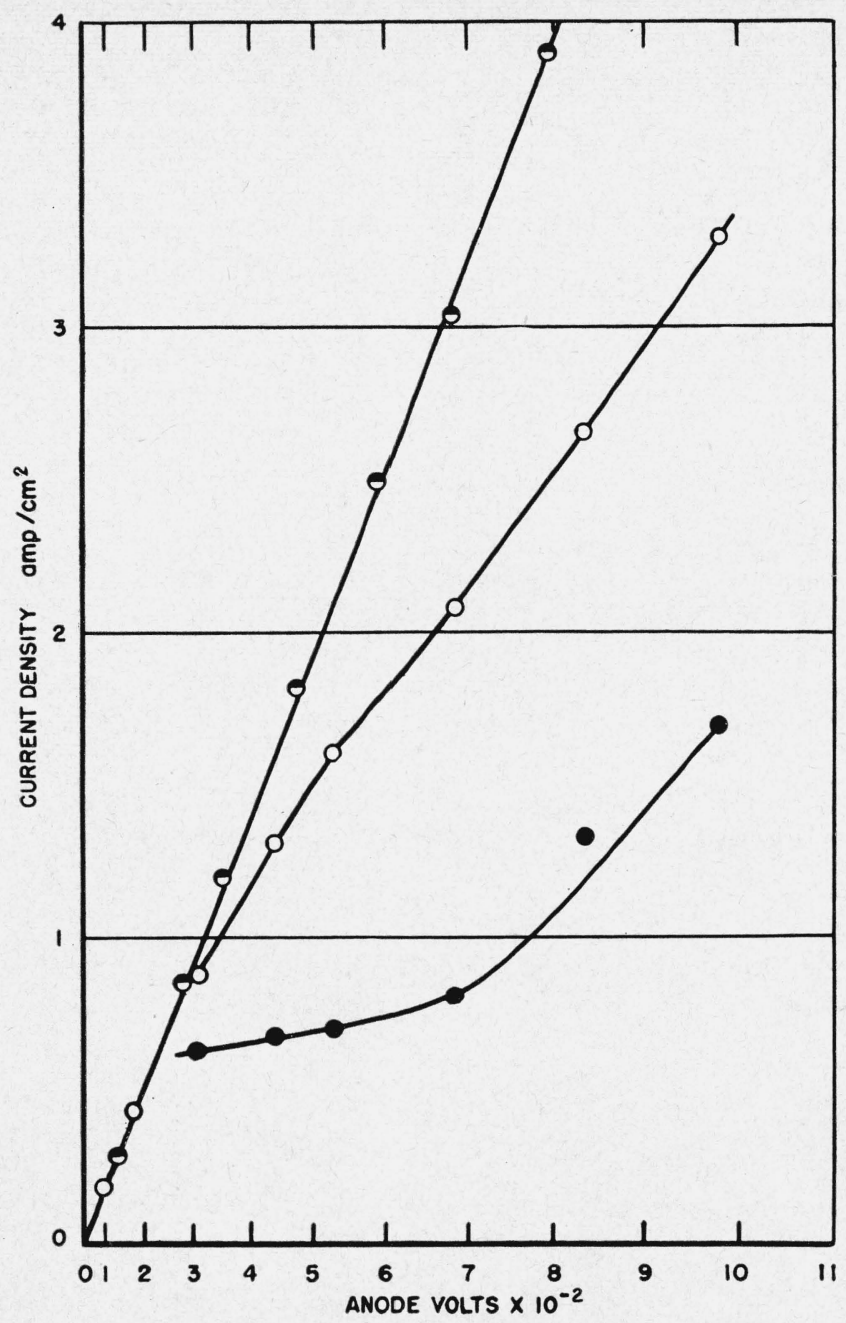

Figure 9. Effect of cathode treatment on pulse-current decay. Open and filled circles represent data before pulse aging. Half-filled circles represent data taken after pulse aging.

may be considered to be fairly strong evidence that the causes of decay were in the cathode itself. They are not conclusive, however, because one cannot be sure that bombardment of the anode with $300-v$ electrons did not indirectly affect the decay.

Mention has already been made of the fact that at certain times during the life test of the watercooled tube pulse measurements were made (see figs. $6, b$ and $7, b)$. A very interesting and significant fact in connection with these tests is that there never was any evidence whatever of pulse-current decay. It was somewhat surprising that such evidence did not appear in the later tests, as it was thought that changes occurring in the cathodes and at the surfaces of the anodes during several hundred hours of operation might bring about conditions that would cause decay. It should be pointed out that early in the life of this tube, before the life test was started, it was possible to induce decay by heating the cathodes to a high temperature. This decay was removed by heating the anodes and ageing the cathode.
The amount of information concerning pulsecurrent decay presented here is hardly enough to justify any very conclusive statement regarding it. However, one may say that the information supports the view that decay, of the kind described here, is associated with conditions that exist during the activation period and early life but may not appear during the normal operation of a properly processed tube.

The need for an accelerated direct-current life test is often pointed out by those who use tubes in large quantities, as for instance defense agencies. A difficulty encountered in setting up an accelerated test for emission is the establishment of conditions that permit correlation of results with those found under actual operating conditions. This being so, one may be justified in a little speculation concerning a possible application of the decay effect to this problem.

Suppose a tube when delivered to the user is subjected to a pulse test, the pulse being square and of relatively long duration. At sufficiently low values of voltage the current pulse will doubtless be square, and its magnitude will satisfy the space-charge equation. As the peak voltage is raised either of two things may happen; decay may appear in the current pulse, or the current may reach the temperaturelimited value and deviate from the space-charge line without evidence of decay. Performance of the first type would indicate inadequate or improper processing of the tube, not necessarily of the cathode alone. Performance of the second type would be indicative of a properly processed tube, and if the break from the space-charge line occurs at a value of current considerably above the direct-current operating value, one might expect long life. Tubes tested in this way could be life tested later under actual conditions to establish a correlation. It is realized, of course, that the greater structural complexity of the usual vacuum tube may make it difficult or impossible to apply such a test. One essential condition to be met in the test would be that of controlling the duty cycle so that the average power input to the tube structures outside the cathode would never go above that in the specified direct-current operation.

\section{Summary}

Details of an experimental method for determining the relative merits of two oxide cathodes, one on a base of high purity nickel, the other on a base of nickel containing a small amount of magnesium, have been presented. A guiding purpose in the design of the apparatus and in the establishment of processing and test procedures was to remove, actually or effectively, a maximum number of those factors that might introduce uncertainty into the interpretation of results.

The study of conditions associated with the appearance and disappearance of pulse-current decay leads one to conclude that this effect may prove to be a useful tool in evaluating the initial quality of a tube. Uncertainty exists as to the location of the 
causes of this effect. They may be in the cathode, in the anode, or in both cathode and anode. Further work will be required to resolve this difficulty.

The authors express their appreciation to J. E. White for many helpful discussions and suggestions, and to all those members of the Tube Laboratory who have given assistance in the work. We also thank M. L. Greenough and W. E. Williams, of the Electronics Instrumentation Laboratory, for designing and constructing the pulser used in these experiments.

\section{References}

[1] M. Benjamin, Phil. Mag. 20, 1 (1935).

[2] E. F. Lowey, Phys. Rev. 35, 1367 (1930).
[3] E. M. Wise, Proc. IRE 25, 714 (1937).

[4] F. Violet and J. Reithmuller, Annales De Radioelectricite IV, No. 17 (1949).

[5] A. H. White, J. Appl. Phys. 20, 856 (1949).

[6] J. R. Dillinger, University of Wisconsin, PhD Thesis (1947).

[7] E. A. Coomes, J. Appl. Phys. 17, 647 (1946).

[8] D. A. Wright, Proc. Roy, Soc. London 190, 412 (1947).

[9] Bell Telephone Laboratory Report, Emission \& life studies of four cathode nickel with different magnesium content (Feb. 15, 1949). Unpublished.

[10] A. Eisenstein, J. Appl. Phys. 20, 776 (1949).

[11] R. L. Sproull, Phys. Rev. 6\%, 166 (1945).

[12] S. Wagener, Proc. Phys. Soc. 61, 521 (1948).

[13] G. R. Feaster, J. Appl. Phys. 20, 415 (1949).

[14] D. A. Wright, Proc. Phys. Soc. 62, 398 (1949).

[15] G. H. Metson, Phys. Soc. Proc. 62B, 589 (1949).

Washington, August 25, 1950. 